\title{
The elements of political communication on Facebook
}

\author{
Assist. Prof. PhD. Tănase Tasențe \\ "Ovidius" University of Constanta, Romania \\ office@pluscommunication.eu
}

\begin{abstract}
In its role as a tool that facilitates participation, Facebook acts as a channel of political communication with different mechanisms than traditional media. At the same time, Facebook offers new means of receiving the audience, characterized by a targeting of the very good target audience. The Facebook page of a political party facilitates interaction and political participation, making possible a two-way communication model and facilitating increased political participation of public opinion. The platform is not mediated and has no boundaries as traditional media has, which means that parties have direct access to more people than ever. Moreover, it is also noted that, on Facebook, the political message does not go through the editorial policy filters as it happens in traditional media and is used as a powerful interaction tool with the target audience or even with a public not ever considered by the political communication strategies.
\end{abstract}

Keywords. political actors; reputation management; online voters; engagement rate; interaction

\section{Political actors and reputation management in online environment}

Facebook has become a platform not only for socializing between different individuals, but also an extremely important platform for promoting the image of political actors. In fact, concepts such as building, maintaining and repairing the image or increasing the social image's capital, known concepts in Public Relations, Advertising and Marketing and applied in the real world, in Social Media (especially on Facebook) have been replaced by "reputation management".

Thus, the term "image" is transformed into "reputation", which represents the more visible, more palpable part of the image, "in the event that the public does not accept the image in its multiple dimensions, but accepts only the key and most visible aspects (audiences become more and more superficial in the conditions of informational abundance)" (Cismaru, 2012). For example, on Facebook, you can not quantify all the dimensions of the image of the political actors, but after the debates, the comments received from other users or even the photos, the politicians remain in the minds of those users or groups of users with the key and most visible aspects of image, which is the reputation.

Moreover, the reputation management focuses primarily on the idea that, whether real environment is the space in which they act like a public figure, the online channel is the one that is recording, filtering and translating into effects on image level these actions.

This paradigm "the real environment vs. virtual environment" has reversed because Facebook users have increasingly begun to use online data as a source of information and 
documentation. Facebook, along with Google, has become the most popular tool for systematizing and processing information about a political actor or an organization, and has given the online environment the opportunity to consecrate, promote, label, or remove an actor from the real-world public space.

The novelty of reputation management is given by the fact that all communication channels can be managed and one image can be created from a single perspective, and not from many, as is the case with classic imaging strategies and techniques. With this single perspective - that is, a single strategy - two benefits are gained: "faster image building (due to convergence of actions) and greater clarity (due to unity of objectives)" (Cismaru, 2012).

The main tool used in a reputation management plan is to create a means of communication that can be $100 \%$ controlled by the one who manages its reputation. The end result of this program is building trust, which is based on the "integrity" of the character or organization: unconditional orientation for the public good, congruence between internal and external communication and transparency.

Thus, the online environment that is $100 \%$ controlled by the reputation manager has become the Facebook page where the online audience can get the "fan" status of the politician or organization with one click. This mechanism has also made the distinction between reputation and image. Reputation has become an "essential image" (Cismaru, 2012): those indistinct indicators with a strong positive or strongly negative value (high visibility, either positive or negative and stable over time).

\section{Online voters and their features}

Facebook voters have a "profile", namely a digital representation of self. They can post photos with them and their friends, join and form groups with other users who share the same beliefs and opinions. The user profile contains several variables that strategies and other members of the campaign teams can exploit for easier and more effective communication with them.

Generally, if this data was not set by the user as confidential, the profile shows data about: age (exact date of birth), place of residence, place of birth, current and former jobs, positions occupied by or occupied in their lifetime, detailed data on their level of education (high school, college, PhD. etc. - and time periods in which they have completed) the languages that they know, religious orientation, political orientation, relationship status (single, in a relationship, married, divorced, etc.), family members who have Facebook profiles, the Facebook pages they appreciate, their group of friends, the read books, the watched movies, the places they visit, the music they listen to the TV shows they are watching, the personalities they are appreciates their most, their hobbies and contact details. In addition to these variables, strategists can also take into account the topic of the photos or of the videos they post.

All of these indicators can be considered to create a personality of potential voter and, of course, to create personalized messages that can meet certain needs, which may stir some curiosity. In order to convince, the political actor must know his electorate very well. If the offline voter is hard to analyze, in the virtual environment, the political actor can know a lot about his voters' life and the interests they develops on certain topics.

\section{Online opinion leaders and influencing the political communication}

The online opinion leaders or the online political citizens (O.P.C.) differ considerably from classical opinion leaders. First of all, the online opinion leaders are not well-known compared to traditional ones. Secondly, the O.P.C. often have strong links in their social 
network, compared to traditional opinion leaders who rely heavily on weak links. By making a comparison, we could say that the online opinion leaders, even if they do not enjoy the reputation of traditional ones, have more powerful connections (due to the environment in which they operate) and thus we can admit that they also have a greater influence.

Usually, the O.P.C. are fans of the politician's Facebook page, they track their political activities, they debate with other fans of the politicians and they decentralize all political communication in their social groups. In the context of developing of the online social networking, especially on Facebook, the O.P.C. become extremely important as they become real communicators of the politician and have the power to influence their social group (strong links) to the approval or disapproval of an idea that the political actor expresses.

\section{Social groups and virtual communities}

The online social groups are strong links and weak links of Facebook users. Simply put, the social groups are the "friends" they have on their list and which, according to Facebook policy, the user knows them from real life. The online social groups are not based on the common interests of members, but rather on other considerations, such as: they are friends and in real life, they are colleagues of work, school etc. Virtual communities differ from online social groups precisely because they are based on common interests that members have. For example, there are virtual communities of supporters of a political party, of a social cause etc. On the other hand, the online social groups are part of a Facebook user and are not constant and similar from one user to another. In order to propagate and influence the political message, the social groups of O.P.C. are one of the most important elements, because the O.P.C., through their interpersonal communication, they can influence many members of their social group to become the fan of the politican and to influence, in their turn, their social groups.

\section{The political message and its personalization on Facebook}

Facebook's political message is built on a specific pattern, much different from the official pattern of the political discourse, as we can see it on television or we can read it in newspapers. First of all, the style of the political message transmitted via Facebook is informal, even colloquial, sometimes, and any attempt by a political actor to convey political messages with formal language is doomed of failure, from the point of view of the feedback.

Viewed from the perspective of the topic used, political actors in the online environment - as well as in the offline environment - are helped by certain "non-political" events that they include in their public discourse. On Facebook, the non-political events used by the politician to politicize them (voiced or by the nature of the emitter) have an essential role in increasing the adherence of online voters to their Facebook page; and this is because online audiences use this social network more for leisure and entertainment than as a means of discussing political or public interest themes. The principle of using entertainment in political communication is also called infotainment and has been adopted since the third phase of the development of political communication systems, the so-called "americanization".

\section{Interactions of the public online and methods of centralizing feedback}

The major revolution in Facebook communication is that any type of reaction is not in vain and will be known to many social network users. Thus, in the classic political communication systems, feedback from voters was delayed or even non-existent (due to lack of feedback-friendly tools), the Facebook era attaches great importance to public interactions, 
once the public considered only as a "dead end", the last stake in a chain of political communication.

The goal of any person on Facebook, but especially of political actors in relation to voters and potential new voters, is to be likeable. Through a well-established social media strategy, a political actor can quickly become a desirable character from an undesirable one. Throughout this equation, the dialogue or the interaction is a basic indicator. As Horia Mihai Bădău (2011) states, "following repeated exchanges and interactions, accidental visitors can turn into loyal visitors and then into very valuable communication vectors".

Facebook allows its users more ways to centralize and manage the feedback as follows: like, comment and share. All kinds of used method creates interaction. Thus, if a message is liked, commented, or shared by a user, many users from their social group will automatically be notified of their position about the post. This way enhances the degree of interaction and can create a wide-ranging debate not only between the original user and its social group users, but this is extrapolated - if the feedback is high - and to the friends of the user's friends.

A good topic can generate incredible success in Social Media because its users can create a cascade effect in a very short time, and that subject can reach many social network nodes. Moreover, as Moira Burke (2012) recalls in a Facebook psychosocial impact study, "if you use Facebook to communicate with people - by using the like button, comment or share to a friend's post - can increase your image capital". The same researcher makes the difference between personalized messages, called "composite messages", and considers them more effective than using "one-click" communication (eg using only the like button).

However, the political interest and the engagement are two seemingly separate but interdependent concepts. As Verba (1995) states, "it is more likely that engaged users are more interested in politics, and it is also more likely that interested users will be more engaged in politics". This indicates that in our analysis, the engagement will be a basic indicator in calculating the interest of Facebook users in general and the fans of politician's pages, in particular, on political issues.

The success of political actors in Social Media is ensured not only by the large number of fans who have joined it, but also by their engagement to the politician's online activities. Engagement turns a fan into extremely important vector for the politician, because he will because in short-time an online opinion leader. As will be explained below, Facebook is the channel that revolutionizes the entire classical political communication system, meaning that the debate occurs more in the social groups of a politician's fans than on the politician's page. From here, we can only deduce that a great engagement ensures the dissemination of the political message to an extremely large number of Facebook users who may become in the future not only fans of the Facebook page, but also potential voters.

The daily engagement rate (ER) is calculated by dividing the sum of one-day reactions (likes, comments and shares) to the total number of daily posts. The result obtained is divided by the number of fans of the day, according to the following equation:

$$
E R=\frac{\left[\frac{\text { Likes }+ \text { Comments }+ \text { Shares }}{\text { No. of posts }}\right]}{\text { No. of fans }}
$$

\section{References}

[1] Cismaru, D-M. (2012). Social Media şi managementul reputaţiei. Bucharest: Tritonic.

[2] Bădău, H.M. (2011). Tehnici de comunicare în Social Media. Iaşi: Polirom, 155.

[3] Burke, M. apud. Marche, S. (2012). “Is Facebook Making Us Lonely?". The Atlantic. 
https://www.theatlantic.com/magazine/archive/2012/05/is-facebook-making-uslonely/308930/

[4] Verba (1995) apud Stanyer, J. (2010). Comunicarea politică modernă. Politici mediatice în vremuri nesigure. Cluj-Napoca: CA Publishing, 174.

[5] Tasente, T. (2014). Comunicarea politica prin Social Media și reacțiile publicului online. Bucharest: Editura Universitară. 